\title{
The allelopathic effects of Rumex dentatus and Dalbergia sissoo on growth and germination of Brassica campestris $\mathbf{L}$.
}

Shah Khalid ${ }^{1 *}$, Maryam Naseem ${ }^{1}$, Marya Sajjad ${ }^{1}$, Sadaf Riaz ${ }^{1}$, Ujala Ibrahim $^{1}$, Hoor Shumail ${ }^{2}$ and Syed Inzimam Ul Haq ${ }^{1}$

1. Department of Botany, Islamia College Peshawar, KPK-Pakistan

2. Women University Mardan, KPK-Pakistan

*Corresponding author's email: shahkhalid@icp.edu.pk

Citation

Shah Khalid, Maryam Naseem, Marya Sajjad, Sadaf Riaz, Ujala Ibrahim, Hoor Shumail and Syed Inzimam U1 Haq. The allelopathic effects of Rumex dentatus and Dalbergia sissoo on growth and germination of Brassica campestris L. Pure and Applied Biology. Vol. 10, Issue 1, pp199-208. http://dx.doi.org/10.19045/bspab.2021.100021

\begin{tabular}{llll}
\hline \hline Received: 02/06/2020 & Revised: 21/08/2020 & Accepted: 27/08/2020 & Online First: 17/09/2020
\end{tabular}

\section{Abstract}

The present research work was conducted to acquire the allelopathic effect of Rumex dentatus and Dalbergia sissoo in relevance to germination and growth of Brassica Campestris. Fresh and dry leaves of $R$. dentatus and D. sissoo $(5 \mathrm{~g}, 10 \mathrm{~g}$ and $15 \mathrm{~g})$ were soaked for 24,48 and 72 hours in $100 \mathrm{ml}$ of water and was filtered by using Whatman filter paper no. 1 . The prepared extract was used against the test plant by observing its impact on the germination percentage, radicle and plumule length after 72 hours of incubation period at $26^{\circ} \mathrm{C}$. The results showed that the extract of $D$. sissoo effected the radicle length more as compared to plumule length while $R$. dentatus significantly effected the radicle length, plumule length and germination percentage. Moreover, the results also illustrated that for D. sissoo the inhibitory effects of fresh leaves on the test plant were more pronounced than the dry leaves extract whereas the inhibitory effects of dried leaves extract of $R$. dentatus on the test plant was more evident than the fresh leaves. The application of $R$. dentatus dry leaves extract completely suppressed the germination percentage, whereas in the case of fresh leaves minimum germination percentage was recorded $20 \%$ in $5 \mathrm{~g}$ (24hrs soaking duration) as compared to control (95\%). In the case of D. sissoo, the fresh and dry leaves extract showed a lesser effect on germination percentage while the application of fresh leaves extract was inhibitorier and showed more reduction in radicle and plumule length. The maximum reduction in the radicle length was recorded $(0.12 \mathrm{~cm})$ and plumule length $(0.05 \mathrm{~cm})$ as compared to control $3.98 \mathrm{~cm}$ and $1.6 \mathrm{~cm}$ in $24 \mathrm{hrs}$ soaking duration. From the results, it was concluded that fresh and dry leaves extract of $D$. sissoo and $R$. dentatus significantly reduces germination and growth of $B$. campestris in comparison to control. The reported inhibitory effects assumed that $D$. sissoo and $R$. dentatus had allelopathic potential which inhibited the growth and development of B. campestris.

Keywords: Allelopathy; Extract; Brassica campestris; Dalbergia sissoo; Rumex dentatus; Germination percentage; Inhibitory effect; Plumule length; Radicle length

\section{Introduction}

The term allelopathy was first coined by physiologist Hans Molish (1937) in his book 'Der Enfluss einer Pflanze auf die Andre (The Effect of Plants on Each
Other)'. It is a Greek word consisting of two words allelon meaning "mutual" and pathos means "suffering or harmful effects on each other [1, 2]. Allelopathy is a biological phenomenon according to which 
one organism produces one or more biochemicals that affects the rate of germination, growth, reproduction and survival of other organisms negatively or positively [3]. Ironically the term Allelochemicals was first used by two scientists Whittaker and Feeny in 1971. According to them "allelochemicals are biochemicals that are of major significance in adaption of species and organization of communities". They have both beneficial (positive allelopathy) or detrimental (Negative allelopathy) effects on the target organisms and community and are responsible for causing allelopathy [3, 4]. They are produced by releasing secondary metabolites and are not required for direct metabolism of allelopathic organisms $[5,6]$. On the basis of chemical simiarities, allelochemicals are distributed from simple hydrocarbons to complex pyrolic compounds. The Allelochemicals are concentration dependent. If present in low concentrations, they may stimulate rather than inhibit the growth. Chemicals with allelopathic potential are present in all plants and in many tissues, such as leaves, flowers, fruits, buds, stems and root [7]. Allelochemicals with negative allelopathy effects are important part of plant defense against herbivory [8]. Pakistan is a country with its economy greatly dependent on forestry and agriculture. Dalbergia sissoo, commonly known as North India Rosewood, is an evergreen rosewood tree extensively found in Punjab Province. It is also known as weed of bush lands at road side [9]. It is found in tropical to subtropical climates in forests mainly near streams, rivers [10, 11]. In Pakistan, Dalbergia is renowned for its ornamental purposes and quantity of timber [12]. It has a strong root system which helps it to control erosion and stabilize the disturbed area [11]. It grows naturally under subtropical climatic condition [13]. Rumex dentatus Linn. is a common weed of cultivated fields is also found extensively in Pakistan. It is ubiquitous in Sindh, Balochistan, Punjab, Rawalpindi and KP region. It usually grows throughout the year but sometimes it is biannual. The seeds are grown by the mid of November and it reaches its maturity by the end of December. The well-developed root system of Rumex dentatus provides an edge over other plants. The leaves are small in the seedling stage which become extremely well in later stage [14]. Brassica oil seeds crops are cultivated on 23 million hectares annually which give over 36 million tones production to the world [15]. It is best known for its important agricultural and horticultural crops and includes a number of weeds. Mustard is the second most important source of oil in Pakistan that contribute to $17 \%$ of the total domestic production of edible oil. [16]. In Pakistan it is cultivated in winter and harvested in March. Further it is cultivated in the alkaline soil and raised in full sun light. It tolerates a $\mathrm{PH}$ from 4.8 to 8.3. Brassica campestris is characterized by high amount of Sulphur and nitrogen compound. Brassica campestris is influential modulator of immune system with potent antiviral, antibacterial, anticancer and antiandrogen [17].

\section{Materials and Methods}

\section{Collection and mechanical processing of plant material}

Fully grown mature leaves of Rumex dentatus and Dalbergia sissoo were collected from areas around the Botany Department of Islamia College Peshawar, Pakistan. From each, half of the leaves were washed thoroughly with distilled water and were placed in a room to dry them with temperature ranging from $14^{\circ} \mathrm{C}$ to $20^{\circ} \mathrm{C}$. The other half of them were crushed using mortar and pestle. The aqueous extracts are made by soaking them in distilled water. 
The extracts were stored at $5-10^{\circ} \mathrm{C}$ when not in use. However, the extracts were used within 24, 48 and 72 hours of its extraction.

\section{Apparatus used}

The apparatus used in the research were: Filter paper, Petri dishes, Incubator, Refrigerator, Beaker, Digital balance, Titration flasks, Funnels, Iron stand, stirrer and Mortar and pestle. All above apparatus were thoroughly washed with tap water, rinsed with distilled water and then finally sterilized in the autoclave machine at $160^{\circ} \mathrm{C}$ for at least 4 hours.

\section{Procurement of seeds of test species}

Brassica campestris variety BGE-5 was used as test specie. The seeds of the test plant were obtained from the institute of Biotechnology and Genetic Engineering, the University of Agriculture, Peshawar.

\section{Standard filter paper bioassay}

After sterilization of Petri dishes, Whatman no. 1 filter paper and cotton were used as the seed-beds in these experiments. Firstly, cotton was spread and placed in the Petri dishes and then Whatman no.1 filter paper was folded twice and placed in the Petri dishes. These filter papers seed-beds were moistened with distilled water for control and with the respective plant extracts (i.e. leaves) for making tests. Excess of extract or distilled water was strictly avoided to reduce the effect of waterlogging on germination and growth of the seedling. Each Petri dish was provided with 5 healthy seeds that were placed at equal distance on the filter paper. The Petri dishes were always sealed with large size Petri dishes or polythene sheets to retain moisture and humidity. Loaded Petri dishes were incubated at $26^{\circ} \mathrm{C}$.

\section{Preparation of aqueous extract}

Five, $10 \mathrm{~g}$ and $15 \mathrm{~g}$ fresh and dry leaves of $R$. dentatus and Dalbergia sissoo each were separately soaked in $100 \mathrm{ml}$ distilled water for 24,48 and 72 hours at $26^{\circ} \mathrm{C}$ and then filtered to get aqueous extract. These extracts were used against $B$. campestris as test species by using the "standard filter paper bioassay" $[18,19]$. The filter papers were moistened with the aqueous extracts, while distilled water was used as a control. Each treatment had 3 replicates, each with five seeds. Petri dishes were incubated at $26^{\circ} \mathrm{C}$. Germination, radicle and plumule growth were recorded after 24,48 and 72 hours.

\section{Standard germination}

The percent germination of the test species was recorded according to Scott [20].

(Germination Percent $=$ no of germinated seeds / total no of seeds x 100)

\section{Statistical analysis}

Each experiment was performed in a completely random design block and results obtained were the average of three replicates. The results were statistically analyzed through significantly different from control at alpha $=0.050$ according to one way ANOVA followed by the student's t-test.

\section{Results and Discussion \\ Germination percentage (\%)}

Reduction was observed in case of germination percentage that was duration and concentration dependent. The percent germination of Brassica campestris was inhibited by the aqueous dry and fresh leaves extract of Rumex dentatus and Dalbergia sissoo. The study indicated that the aqueous dry leaves extract of Rumex dentatus in all treatments showed inhibitory effects on percent germination as compared to fresh leaves extract and fresh and dry leaves extract of D. sissoo. According to the mean value of germination of $B$. campestris the highest percent $(95.3 \%)$ was noted in $72 \mathrm{hrs}$ followed by $48 \mathrm{hrs}(94 \%)$ and $24 \mathrm{hrs}(87 \%)$ of soaking duration in case of $D$. sissoo respectively. However, the lowest percent germination of $B$. campestris was found to be $(46.7 \%)$ in $24 \mathrm{hrs}$ followed by $48 \mathrm{hrs} \quad(74.3 \%)$ and $72 \mathrm{hrs}(86 \%)$ as 
compared to control (100\%) inhibited by $R$. dentatus. Moreover, hours x concentration mean of the germination of $B$. campestris indicated that under control condition lowest inhibition (20\% and 60\%) at $5 \mathrm{~g}$ was recorded in soaking duration of $24 \mathrm{hrs}$ in case of $R$. dentatus while, the highest inhibition $(100 \%)$ at $5 \mathrm{~g}$ and $10 \mathrm{~g}$ was noted extraction duration (48hrs and $72 \mathrm{hrs}$ ) of $D$. sissoo. Even then the result revealed that all treatments (i.e. $5 \mathrm{~g}, 10 \mathrm{~g}$ and $15 \mathrm{~g}$ ) of dry leaves extract of $R$. dentaus in all duration was negatively affected by the germination percentage to $(0 \%)$ as compared to control $(100 \%)$. Finally the result apprises us that extraction of R.dentatus showed complete inhibition whereas $D$. sissoo showed least inhibition in the growth and development of germination percentage (Table 1; Fig. 1). Similarly, the aqueous dry and fresh shoot and root extracts of Rumex dentatus spp. Klotzschianus significantly inhibited the seedling growth and germination percentage of test species as compared to control [21]. The current work was also carried out to look the allelopathic effect of Clerodendrus infortunatum $L$. leaf extract on seed germination and seedling growth of some agricultural crops such as Triticum aestivum (wheat), Brassica campestris (mustard), Vigna radiata (mung bean) etc. It was found that aqueous leaf extract of $C$. infortunatum L. completely inhibited the germination percentage of tested crops [22]. The effect of aqueous extract from Calotropis procera on the growth of Brassica specie. The effect of extract was studied against germination percentage, seedling growth and dry biomass. Result concluded that higher concentration extracts significantly reduced germination percentage, radicle length and plumule length of Brassica seedling as compared to control [23]. Likewise, another work also evaluated that aqueous extract of walnut leaf significantly inhibited seed germination and seedling growth of $B$. campestris. Hence seed germination and seedling of mustard were affected negatively by walnut leaf extract [24]. Parallelly, some other experiment also evaluated the allelopathic potential of leaf aqueous extract obtained from Cynara candunculus $L$. plant species on germination of $B$. campestris used as a test specie on average the aqueous leaf extracts significantly reduced the final percentage of seed germination as compared to control [25].

Table 1. Effect of 24, 48 and 72 hours soaking duration extract of Rumex dentatus and Dalbergia sissoo at $5 \mathrm{~g}, 10 \mathrm{~g}$ and $15 \mathrm{~g}$ fresh and dry leaves on Germination percentage of Brassica campestris $L$. FLE= Fresh leaves extract, DLE= Dry leaves extract. Bars represents significance difference at $\mathbf{P}=\mathbf{0 . 0 5}$

\begin{tabular}{|c|c|c|c|c|c|c|c|c|c|c|c|c|}
\hline \multirow{3}{*}{$\begin{array}{c}\begin{array}{c}\text { Incubatio } \\
\text { n period }\end{array} \\
\text { Treatments }\end{array}$} & \multicolumn{6}{|c|}{ Rumex dentatus } & \multicolumn{6}{|c|}{ Dalbergia sissoo } \\
\hline & \multicolumn{2}{|c|}{$24 \mathrm{hr}$} & \multicolumn{2}{|c|}{$48 \mathrm{hr}$} & \multicolumn{2}{|c|}{$72 \mathrm{hr}$} & \multicolumn{2}{|c|}{$24 \mathrm{hr}$} & \multicolumn{2}{|c|}{$48 \mathrm{hr}$} & \multicolumn{2}{|c|}{$72 \mathrm{hr}$} \\
\hline & $\begin{array}{c}\text { FL } \\
\text { E }\end{array}$ & $\begin{array}{c}\text { DL } \\
\text { E }\end{array}$ & $\begin{array}{c}\text { FL } \\
\text { E }\end{array}$ & $\begin{array}{c}\text { DL } \\
\text { E }\end{array}$ & $\begin{array}{c}\text { FL } \\
\text { E }\end{array}$ & $\begin{array}{c}\text { DL } \\
\text { E }\end{array}$ & $\begin{array}{c}\text { FL } \\
\text { E }\end{array}$ & $\begin{array}{c}\text { DL } \\
\text { E }\end{array}$ & $\begin{array}{c}\text { FL } \\
\text { E }\end{array}$ & $\begin{array}{c}\text { DL } \\
\text { E }\end{array}$ & $\begin{array}{c}\text { FL } \\
\text { E }\end{array}$ & $\begin{array}{c}\text { DL } \\
\text { E }\end{array}$ \\
\hline Control & 95 & 0 & 100 & 0 & 100 & 0 & 98 & 98 & 100 & 100 & 100 & 100 \\
\hline $5 \mathrm{~g}$ & 20 & 0 & 60 & 0 & 86 & 0 & 98 & 98 & 100 & 100 & 100 & 100 \\
\hline $10 \mathrm{~g}$ & 60 & 0 & 83 & 0 & 86 & 0 & 98 & 98 & 100 & 100 & 100 & 100 \\
\hline $15 \mathrm{~g}$ & 60 & 0 & 80 & 0 & 86 & 0 & 65 & 65 & 82 & 82 & 86 & 86 \\
\hline Mean & $\begin{array}{c}46 . \\
7\end{array}$ & 0.0 & $\begin{array}{c}74 . \\
3\end{array}$ & 0 & 86 & 0 & 87 & 87 & 94 & 94 & $\begin{array}{c}95 . \\
3\end{array}$ & $\begin{array}{c}95 . \\
3\end{array}$ \\
\hline
\end{tabular}




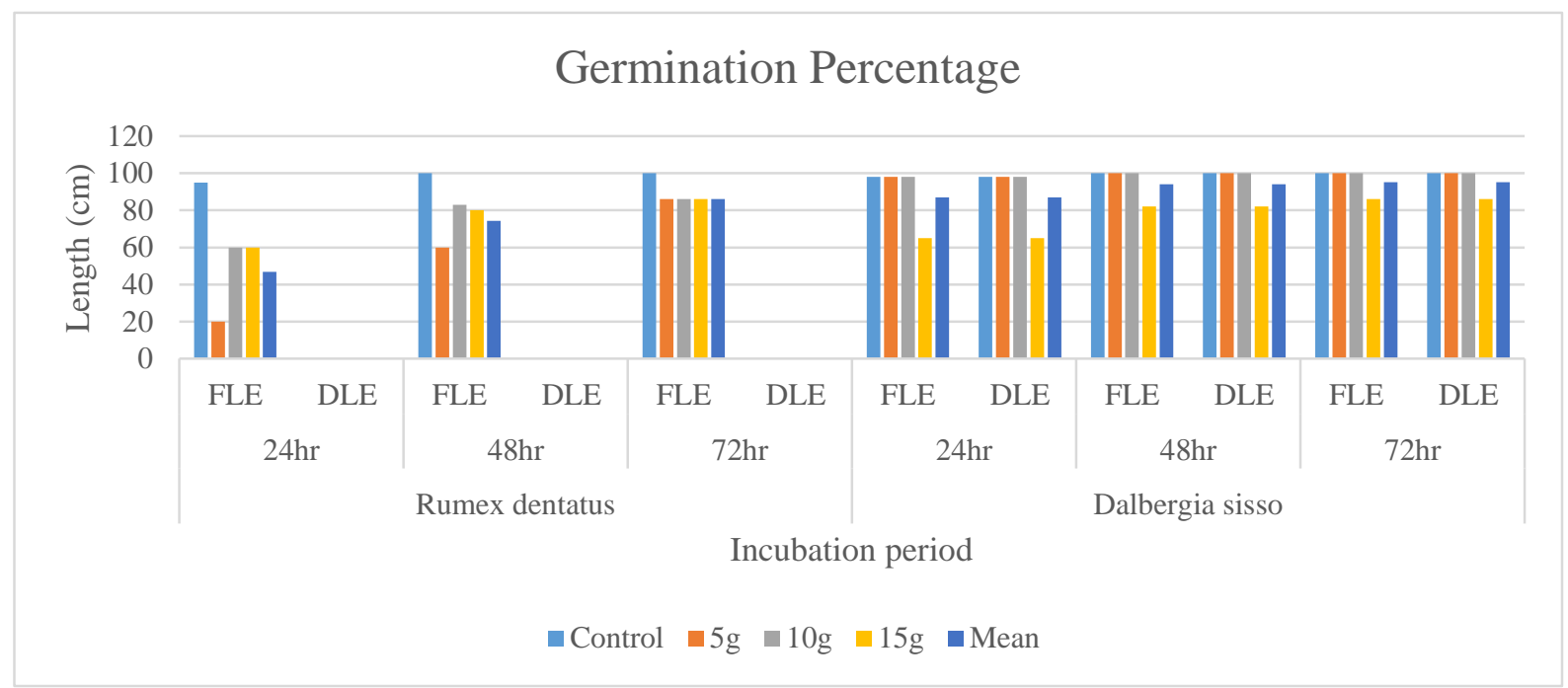

Figure 1. Effect of 24, 48 and 72 hours soaking duration extract of Rumex dentatus and Dalbergia sissoo at $5 \mathrm{~g}, 10 \mathrm{~g}$ and $15 \mathrm{~g}$ fresh and dry leaves on Germination percentage of Brassica campestris $L$. FLE= Fresh leaves extract, DLE= Dry leaves extract. Bars represents significance difference at $\mathbf{P}=0.05$

\section{Radicle length (cm)}

The statistical analysis of radicle length illustrated the significant deviation in duration and concentration mean. The results clearly showed that all the treatments of fresh and dry leaves extract of $R$. dentatus and $D$. sissoo considerably affected the radicle length of $B$. campestris. Further it was observed that the dry leaves extract of $R$. dentatus stands out to be more inhibitory in all treatments. It is so because it completely suppresses the radicle length of B. campestris, comparative to fresh and dry leaves extract of D. sissoo (Table 2; Fig. 2). Moreover the results gave the same maximum radicle length value of $(0.81) \mathrm{cm}$ inhibition in $72 \mathrm{hrs}$ of soaking duration as well as in $48 \mathrm{hrs}$ of soaking duration respectively but for $24 \mathrm{hrs}$ of soaking time the radicle length was recorded as $(0.50) \mathrm{cm}$ inhibition in $B$. campestris for dry of $D$. sissoo. The minimum inhibition was observed in case of $R$. dentatus which reduced the radicle length to $(0.51) \mathrm{cm}$ at $24 \mathrm{hrs}$ duration followed by $(0.54) \mathrm{cm}$ in 48hrs and $(0.80) \mathrm{cm}$ in $72 \mathrm{hrs}$ respectively. The extracts obtained from $15 \mathrm{~g}$ fresh leaves of $D$. sissoo was more significant for radicle length of $B$. campestris which reduced the radicle length to $(0.12) \mathrm{cm}$ after $24 \mathrm{hrs}$ of incubation followed by $48 \mathrm{hrs}(0.23)$ $\mathrm{cm}$ except for $72 \mathrm{hrs}$ duration in which the $R$. dentatus showed more inhibition i.e. (0.73) $\mathrm{cm}$ length. The results showed that $5 \mathrm{~g}$ dry leaves of $D$. sissoo was least inhibitory as it contracted the radicle length by (1.19) $\mathrm{cm}$ in $72 \mathrm{hrs}$ followed by $(1.5) \mathrm{cm}$ in $48 \mathrm{hrs}$ and $(0.98) \mathrm{cm}$ in $24 \mathrm{hrs}$ of time subsequently. The overall result proved that $R$. dentatus is comparatively more inhibitory in comparison to D. sissoo. In the same fashion the Hulless barley (Hordeum vulgare) and its 66 varieties were tested. Its two varieties (Qing 0039 and Qing 0415) significantly reduced the root length in $B$. campestris. Results revealed that inhibition was drastic (100\% inhibition) in radicle length [26]. Similarly, the allelopathic influence of Terminalia belerica Roxh on the Brassica campestris seed. The fresh and dry aqueous 
extract of leaves and fruits from $T$. belerica were tested on $B$. campestris that affects the radicle length of the seed. Percent germination was also inhibited to aqueous extract of the leaves but the radicle length was more significantly reduced as compared to control [27].The aqueous leaf extract of A. conyzodes L. completely inhibited the germination and radicle extension of Brassica campestris [28].Similarly the root and shoot growth of two winter crops (Triticum aestivum and Brassica campestris) and some associated weeds had been significantly reduced by the extract obtained from Artemisia dubia [29]. Similarly the allelopathic effect of Parthenium hysterophorus leaves extract against some cultivated and wild herbaceous spp. They reported that the $P$. hysterophorus leaves extract completely reduced the germination and root elongation of seedling in cereal and shoot elongation in crucifers and wild members Asteraceae [30].

\section{Plumule length $(\mathbf{c m})$}

After statistical analysis the plumule length portrays significant differences between duration and concentration mean. The results showed that all the treatments of fresh and dry leaves extract of $R$. dentatus and $D$. sissoo significantly effected the plumule length of $B$. campestris. Moreover, it was also found that all treatments of dry leaves extract of $R$. dentatus in all duration completely suppressed the plumule length of
B. campestris in comparison to control, fresh and dry leaves extract of D. sissoo (Table 3; Fig. 3). According to mean value, the plumule length of $B$. campestris was observed for dry leaves extracts of $D$. sissoo as relative maxima which gives an inhibition of (1.36) $\mathrm{cm}$ in $72 \mathrm{hrs}$ of soaking duration followed by $(1.25) \mathrm{cm}$ inhibition in $48 \mathrm{hrs}$ and $(1.03) \mathrm{cm}$ inhibition in $24 \mathrm{hrs}$ of soaking time respectively. Contrarily to it minimum inhibition was noticed in case of $R$. dentatus which reduced the plumule length to $(0.29)$ $\mathrm{cm}$ at $24 \mathrm{hrs}$ followed by $(0.48) \mathrm{cm}$ in $48 \mathrm{hrs}$ and $(0.90) \mathrm{cm}$ in $72 \mathrm{hrs}$ of soaking time.

Furthermore the extract obtained from $15 \mathrm{~g}$ of fresh leaves of $D$. sissoo was found out to be more significant for plumule length of $B$. campestris which also reduced the plumule length to $(0.05) \mathrm{cm}$ after $24 \mathrm{hrs}$ of incubation followed by $(0.18) \mathrm{cm}$ in $48 \mathrm{hrs}$ and $(0.23) \mathrm{cm}$ in $72 \mathrm{hrs}$ of soaking duration respectively. Finally, the results demonstrate that $5 \mathrm{~g}$ and $10 \mathrm{~g}$ dry leaves extract of $D$. sissoo was least inhibitory in the afore mentioned parameters which also gives a reduced plumule length of $(1.61) \mathrm{cm}$ in $5 \mathrm{~g}$ and $(1.92) \mathrm{cm}$ in $10 \mathrm{~g}$ as compared to control. However, the entire results justify that the dry extracts of $R$. dentatus showed more inhibitory effects on plumule length of B. campestris as compared to D. sissoo which also seems to more radicle and operative in plants.

Table 2. Effect of 24, 48 and 72 hours soaking duration extract of Rumex dentatus and Dalbergia sissoo at $5 \mathrm{~g}, 10 \mathrm{~g}$ and $15 \mathrm{~g}$ fresh and dry leaves on Radicle length of Brassica campestris $L$. FLE = Fresh leaves extract, DLE= Dry leaves extract. Bars represents significance difference at $\mathbf{P}=\mathbf{0 . 0 5}$

\begin{tabular}{|c|c|c|c|c|c|c|c|c|c|c|c|c|}
\hline \multirow{2}{*}{$\begin{array}{c}\text { Incubation } \\
\text { period } \\
\end{array}$} & \multicolumn{6}{|c|}{ Rumex dentatus } & \multicolumn{6}{|c|}{ Dalbergia sissoo } \\
\hline & \multicolumn{2}{|c|}{$24 \mathrm{hr}$} & \multicolumn{2}{|c|}{$48 \mathrm{hr}$} & \multicolumn{2}{|c|}{$72 \mathrm{hr}$} & \multicolumn{2}{|c|}{$24 \mathrm{hr}$} & \multicolumn{2}{|c|}{$48 \mathrm{hr}$} & \multicolumn{2}{|c|}{$72 \mathrm{hr}$} \\
\hline Treatments & FLE & DLE & FLE & DLE & FLE & DLE & FLE & DLE & FLE & DLE & FLE & DLE \\
\hline Control & 3.98 & 3.98 & 4.15 & 4.15 & 4.38 & 4.38 & 3.98 & 3.98 & 4.15 & 4.15 & 4.38 & 4.38 \\
\hline $5 \mathrm{~g}$ & 0.93 & 0 & 1.08 & 0 & 1.17 & 0 & 0.17 & 0.98 & 0.33 & 1.5 & 0.45 & 1.19 \\
\hline $10 \mathrm{~g}$ & 0.25 & 0 & 0.22 & 0 & 0.51 & 0 & 0.43 & 0.36 & 0.67 & 0.58 & 0.82 & 0.81 \\
\hline $15 \mathrm{~g}$ & 0.36 & 0 & 0.33 & 0 & 0.73 & 0 & 0.12 & 0.16 & 0.23 & 0.34 & 0.31 & 0.44 \\
\hline Mean & 0.51 & 0.00 & 0.54 & 0.00 & 0.80 & 0.00 & 0.24 & 0.50 & 0.41 & 0.81 & 0.53 & 0.81 \\
\hline
\end{tabular}




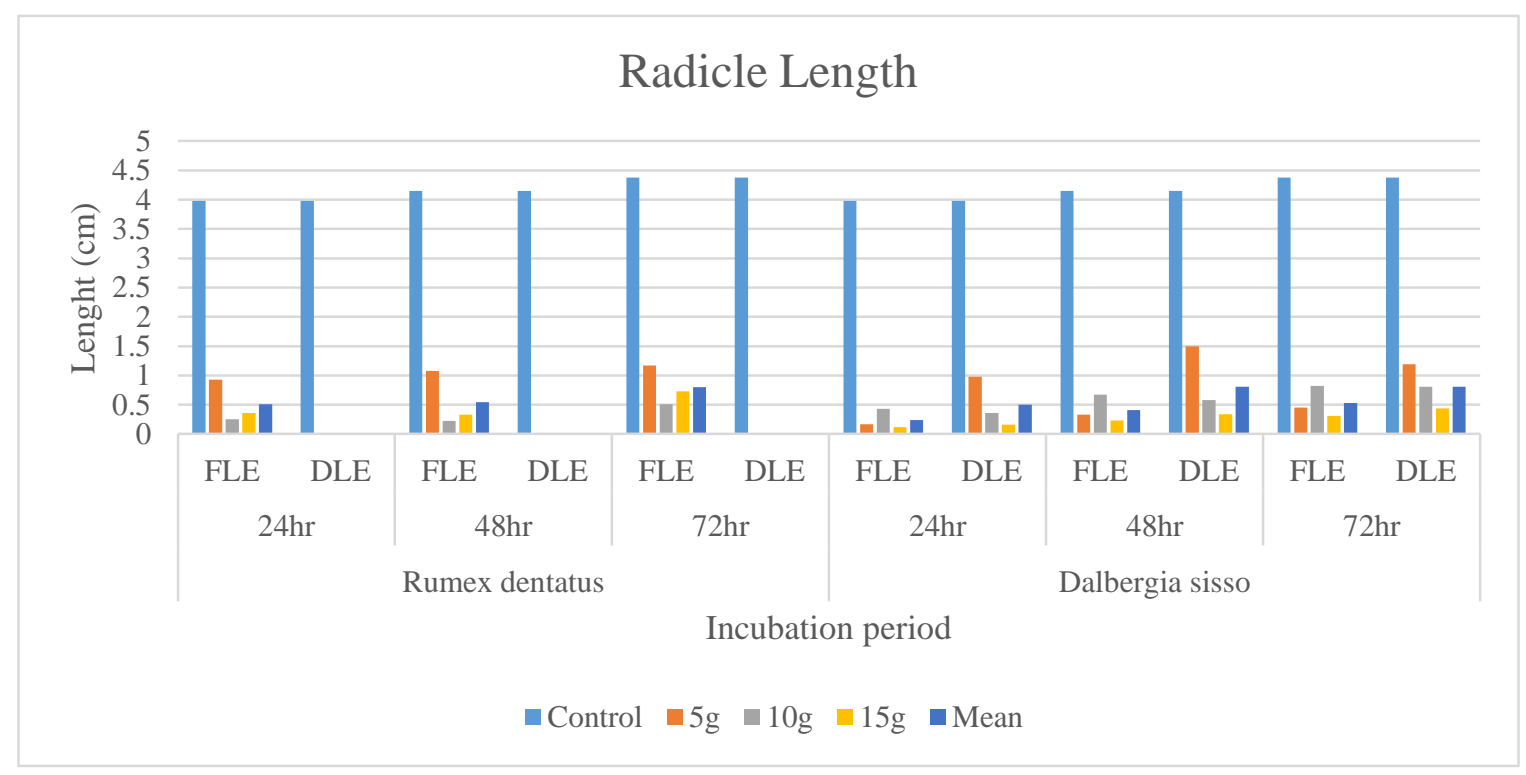

Figure 2. Effect of 24, 48 and 72 hours soaking duration extract of Rumex dentatus and Dalbergia sissoo at $5 \mathrm{~g}, 10 \mathrm{~g}$ and $15 \mathrm{~g}$ fresh and dry leaves on Radicle length of Brassica campestris $L$. FLE $=$ Fresh leaves extract, DLE = Dry leaves extract. Bars represents significance difference at $\mathbf{P}=\mathbf{0 . 0 5}$

In the same manner laboratory work were performed to investigate the allelopathic potential of Forskeolea tenacissema. He used B. campestris as test specie. The aqueous fresh and dry leaves and stem extract from $F$. tenacissema was used against B. campestris. Aqueous extract was used to notice the effect of plumule length and seedling of the seed. Result indicated that aqueous extract invariably reduced plumule length of test specie. Leaves extract prove more toxic than stem, as it significantly inhibits plumule length [31]. It was also observed that when aqueous dried and fresh leaves extract of Quercus glauca Thunb and Leuconrichophora A. Camus were applied on three crops such as, Triticum aestivum, Brassica campestris and Len culinaris, as a result they suppressed the germination, plumule and radicle length of all test crops [32]. Likewise, an experiment performed to evaluate the allelopathic potential of fresh and dry extract from leaves and inflorescence of Parthenium hysterophorus on $B$. campestris. A marked reduction in plumule length indicated toxicity of extract in the leaves. Germination percentage was also inhibited but as compared the plumule length was more significantly reduced as compared to control [33]. Same result was also found that the aqueous leaf and root extract of Cassia tora extremely suppressed the seed germination and growth of B. campestris. There are some earlier workers which reported that, The effect of inhibition was enhanced with increasing plant material. The results showed similarity with results of various researches [34]. It's a general conception that allelochemicals may reverse its effect as per the concentration, as reported many times that enhanced concentration some time cause positive effects, then negative. 
Table 3. Effect of 24, 48 and 72 hours soaking duration extract of Rumex dentatus and Dalbergia sissoo at 5g, 10g and 15g fresh and dry leaves on Plumule length of Brassica campestris $L$. FLE $=$ Fresh leaves extract, DLE $=$ Dry leaves extract. Bars represents significance difference at $\mathbf{P}=\mathbf{0 . 0 5}$

\begin{tabular}{|c|c|c|c|c|c|c|c|c|c|c|c|c|}
\hline \multirow{2}{*}{$\begin{array}{c}\text { Incubation } \\
\text { period }\end{array}$} & \multicolumn{6}{|c|}{ Rumex dentatus } & \multicolumn{6}{|c|}{ Dalbergia sissoo } \\
\hline & \multicolumn{2}{|c|}{$24 \mathrm{hr}$} & \multicolumn{2}{|c|}{$48 \mathrm{hr}$} & \multicolumn{2}{|c|}{$72 \mathrm{hr}$} & \multicolumn{2}{|c|}{$24 \mathrm{hr}$} & \multicolumn{2}{|c|}{$48 \mathrm{hr}$} & \multicolumn{2}{|c|}{$72 \mathrm{hr}$} \\
\hline Treatments & FLE & DLE & FLE & DLE & FLE & DLE & FLE & DLE & FLE & DLE & FLE & DLE \\
\hline Control & 1.6 & 1.6 & 2.33 & 2.33 & 2.91 & 2.91 & 1.6 & 1.6 & 2.33 & 2.33 & 2.91 & 2.91 \\
\hline $5 \mathrm{~g}$ & 0.23 & 0 & 0.59 & 0 & 0.77 & 0 & 0.56 & 1.23 & 0.89 & 1.45 & 0.97 & 1.61 \\
\hline $10 \mathrm{~g}$ & 0.41 & 0 & 0.42 & 0 & 1.12 & 0 & 1.05 & 1.48 & 1.14 & 1.83 & 1.26 & 1.92 \\
\hline $15 \mathrm{~g}$ & 0.23 & 0 & 0.26 & 0 & 0.52 & 0 & 0.05 & 0.39 & 0.18 & 0.46 & 0.23 & 0.54 \\
\hline Mean & 0.29 & 0.00 & 0.42 & 0.00 & 0.90 & 0.00 & 0.55 & 1.03 & 0.74 & 1.25 & 0.82 & 1.36 \\
\hline
\end{tabular}

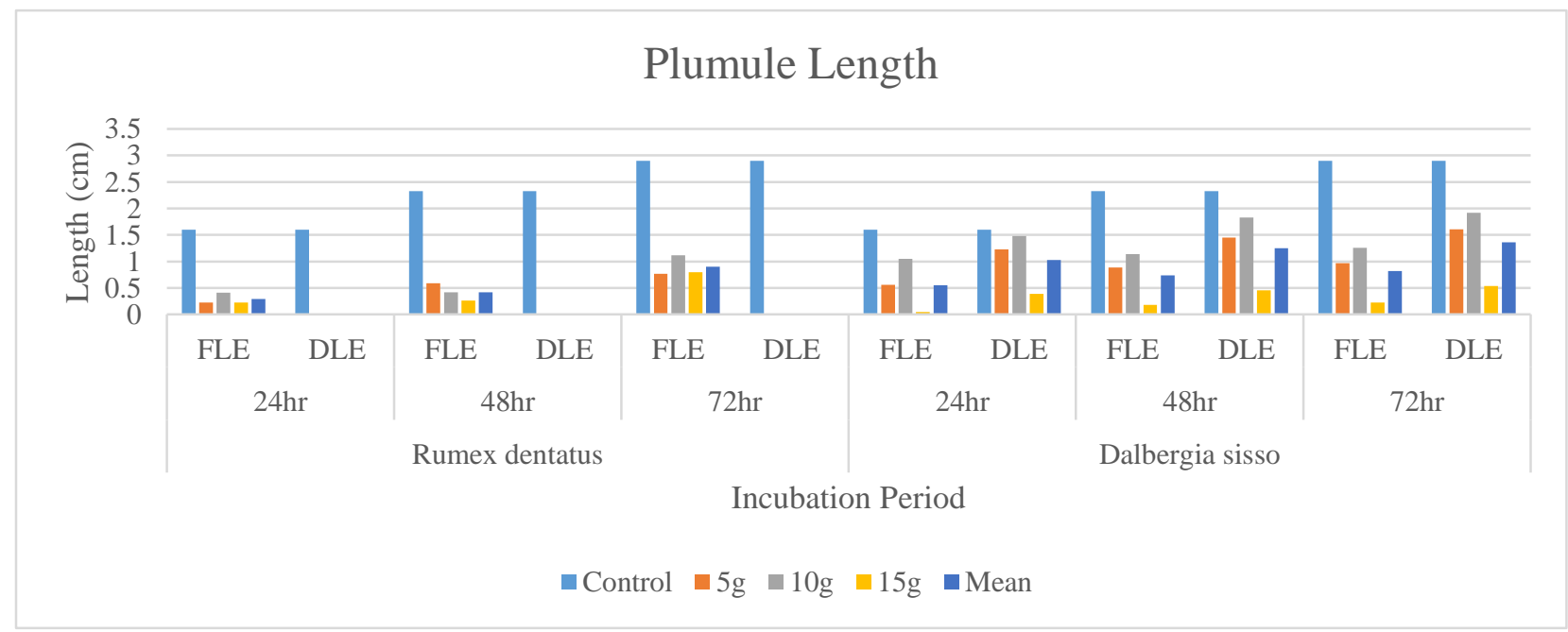

Figure 3. Effect of 24, 48 and 72 hours soaking duration extract of Rumex dentatus and Dalbergia sissoo at $5 \mathrm{~g}, 10 \mathrm{~g}$ and $15 \mathrm{~g}$ fresh and dry leaves on Plumule length of Brassica campestris $L$. FLE $=$ Fresh leaves extract, DLE $=$ Dry leaves extract. Bars represents significance difference at $\mathrm{P}=\mathbf{0 . 0 5}$

\section{Conclusion and Recommendations}

The results concluded that both fresh and dry leaves extract of Rumex dentatus and Dalbergia sissoo contain allelochemicals, which significantly reduces the germination percentage, radicle and plumule length of $B$. campestris. It is observed that the dry leaves extract of $R$. dentatus is more inhibitory than the fresh leaves, while fresh leaves extract of $D$. sissoo was found to be more toxic than dry leaves extract. The toxicity of both plants $(D$. sissoo and $R$. dentatus) is dependent upon the soaking duration as well as concentration. The results evaluate that $15 \mathrm{~g}$ extract is found to be more strenuous followed by $10 \mathrm{~g}$ and $5 \mathrm{~g}$ substantially. This investigation indicated that the most affected part of B. campestris is plumule length is found followed by radicle length. From the experiment and the result, it is far observed that a more inhibitory effect was shown by $R$. dentatus and the least inhibition in the case of D. sissoo. The aqueous leaf extract of $R$. dentatus has more allelochemicals than D. sissoo and could be evaluated as an allelopathic species. From the overall result, it is concluded that $R$. dentatus and $D$. 
sissoo leaves have potential allelochemicals that negatively affects germination percentage and growth parameter of the $B$. campestris. According to the results, it is recommended that Dalbergia sissoo and Rumex dentatus have strong allelopathic impacts on Brassica campestris. Due to this reason both plants should not be cultivated near the $B$. campestris field and further studies should be done to investigate and identify the specific allelochemicals.

\section{Authors' contributions}

Conceived and designed the experiments: S Khalid, M Naseem \& M Sajjad, Performed the experiments: S Khalid, U Ibrahim \& H Shumail, Analyzed the data: S Khalid \& SIU Haq, Contributed materials/ analysis/ tools: M Naseem, M Sajjad, U Ibrahim \& H Shumail, Wrote the paper: S Khalid \& SIU Haq.

\section{References}

1. Rizvi SGH \& Rizvi V (1992). Allelopathy Basic and Applied Aspects. Champman and Hall London. pp. 88.

2. Chon SU \& Nelson CJ (2012). Allelopathic dynamics in resource plants. In: Allelopathy: Current Trends and Future Applications. pp: 81-110.

3. Rice EL (1984). Allelopathy, $2^{\text {nd }}$ edition. Academic press, New York U.S.A. pp. 422.

4. Whittakar RH \& Feeny PP (1971). Allelochemicals: chemical interaction between species. Sci 171(67): 757-770.

5. Farooq M, Jabran K, Cheema Z, Wahid A \& Siddique HMK (2011). The Role of Allelopathy in Agricultural Pest Management. Pest Manag Sci 67(1): 493-506.

6. Bhadoria PBS \& Siddique H (2011). Allelopathy: a natural way towards weed management. Am J of Exp Agric 1(1): 720.

7. Einhelling FA (2009). Interactions among Allelochemicals and other stress factors of the plant Environment. $J$ of Role in Agric and Fores 9(33): 343-357.

8. Stamp N (2010). Out of the quagmire of plant defence hypotheses. The Quarterly Rev of Biol 78(1): 23-55.

9. Morton J (2007). Dalbergia sissoo still a problem 14 years on. Weed Spotters Newsletter. Australia: CRC.

10. Langeland KA \& Stocker RK (2001). Control of Non-Native plants in natural Areas of Florida. SP 242. USA. Florida cooperative Extension service, University of Florida.

11. Duke JA (1983). Medicinal plants of the Bible. Trado-medic books. A Quarterly Rev of Biol 78(1): 23-55.

12. Alam SN, Hossain MI, Rouf FMA, Jhala RC, Patel MG, Rath LK, Sengupta A, Baral K, Shylesha AN, Satpathy S, Shivalingaswamy TM, Cork A \& Talekar NS (2006). Implementation and promotion of an IPM strategy for control of eggplant fruit and shoot borer in south Asia. Tech. Bull. 36. AVRDC Publ. 06-672. AVRDC - The World Vegetable Center, Shanhua, Taiwan.

13. Singh SP (1989). Wasteland development. Financial analysis of selected shelterbelts system in Pakistan. Pak J of Fore 40(3): 247-252.

14. Stewart RR (1972). An annotated catalogue of the vascular plants of West Pakistan and Kashmir. In Nasir E \& SI Ali (eds.), Flora of West Pakistan 1028 pp. Fakhri Press, Karachi.

15. FAO (2004). Agriculture data. Food and Agricultural Organization (UN). Subset D agriculture. Plant Sci 23: 157-174.

16. Song LJ, Thornalley K \& Paul J (2007). Effect of storage, processing and cooking on glucosinolate content of Brassica vegetables. Food and Chem Toxicol 45(2): 216-24.

17. Jain J (2011). Comparative analysis of antibacterial and antifungal activity of five selected Indian medicinal plants on 
Human pathogenic microorganisms. Asian $J$ of Biochem and Pharma Res 1(2): 437-442.

18. Barkatullah, Hussain F, Ibrar M (2010). Allelopathic potential of Dodonaea viscosa (L.) Jacq. Pak J of Bot 42: 23832390.

19. Hussain F, Ahmad B \& Ilahi I (2010). Allelopathic effects of Cenchrus ciliaris L. and Bothriochloa pertusa (L.) A. Camus. Pak J of Bot 42: 3587-3604.

20. Scott SJ, Jones RA \& Williams WA (1984). Review of data analysis for seed germination. Crop Sci 24: 1192-1199.

21. Hussain F, Mobeen F, Kil BS, \& Yoo SO (1997). Allelopathic suppression of wheat and mustard by Rumex dentatus ssp. klotzschianus. $J$ of Plant Biol 40(2): 120-124.

22. Debnath G, Das P \& Saha AK (2017). Allelopathic effect of Clerodendrum infortunatum L. leaf extract on seed germination and seedling growth of some agricultural crops of Tripura, India. Inter Res J of Pharm 8(1): 2230 8407.

23. Gulzar A \& Siddiqui MN (2017). Allelopathic effect of Calotropis procera (Ait) R.Br. On growth and antioxidant activity of Brassica oleracea Var. botrytis. I of the Saudi Soc of Agric Sci 16(4): 375-382.

24. Bahuguna S, Bahugna A \& Singh N (2014). Allelopathic Belongings of Dried walnut leaf on seed germination and seedling Growth of Mustard ( $B$. campestris) in Agri- Silvi system of Uttara Khand Himalaya, India. Am J of Food Technol 9(3): 172-179.

25. Scavo A, Restuccia A \& Onofri A (2018). Allelopathic effect of Cynara cardunculus $\mathrm{L}$. leaf aqueous extracts on seed germination of some Mediterranean weed species. Italian J of Agroecosys Manag 13(2): 119-125.
26. Shen C, Li L \& Chen JY (2005). Discover true association rates in multiportion complex proteomics data sets. IEEE Comput Syst Bioinform Conf. pp 167-74.

27. Bhatt BP, Munesh K \& Todaria NP (1997). Studies on Allelopathic effects of Terminalia species of Gashwal Himalaya. J of Sust Agric 11(1): 71-84.

28. Xuan TD, Shinkichi T, Hong NH, Khanh TD \& Min C (2004). Assessment of phytotoxic action of Ageratum conyzoides L. (billy goat weed) on weeds. Crop Protec 23(10): 915-922.

29. Mallik BBD, Acharya BD, Saquib M \& Chettri M (2015). Allelopathic effect of Artemisia dubia extracts on seed germination and seedling growth of some weeds and winter crops. Ecoprint: An Inter $J$ of Ecol 21: 23-30.

30. Maharjan S, Shrestha BB \& Jhava PK (2007). Allelopathic effect of aqueous Extract of Aqueous extract of leaves of Parthenium Hysterophorous $L$. on seed germination and seedling Growth of some cultivated and wild herbaceous species. Scien World 5(5): 31-33.

31. Naveed S, Hussain F, Khattak I, Khan I \& Barkatullah (2012). Allelopathic Potential of Forsskeolea tenecissema. Inter J of Med and Appl Sci 1(1): 5-14.

32. Bhatt BP \& Chauhan DS (2000). Allelopathic effects of Quercus spp. on crops of Garhwal Himalaya. Allelopathy $J$ 7(2): 265-272.

33. Kumari A, Kohli RK \& Saxena DB (1985). Allelopathic Effects of Parthenium hysterophorus L. Extracts on B. campestris L. Ann of Biol 4(2):189-196.

34. Sarkar E, Chatterjee SN \& Chakraborty P (2012). Allelopathic effect of Cassia tora on seed germination and growth of mustard. Turkish J of Bot 36(5): 488494. 